\title{
Discrepancy in exchangeable and soluble ammonium-induced effects on aerobic methane oxidation: a microcosm study of a paddy soil
}

\author{
Hester van Dijk ${ }^{1} \cdot$ Thomas Kaupper $^{1} \cdot$ Clemens Bothe $^{1} \cdot$ Hyo Jung Lee ${ }^{2} \cdot$ Paul L. E. Bodelier $^{3} \cdot$ Marcus A. Horn ${ }^{1}$. \\ Adrian $\mathrm{Ho}^{1,4}$
}

Received: 25 January 2021 / Revised: 31 May 2021 / Accepted: 12 June 2021 / Published online: 22 June 2021

(c) The Author(s) 2021

\begin{abstract}
Ammonium-induced stimulatory, inhibitory, and/or neutral effects on soil methane oxidation have been attributable to the ammonium concentration and mineral forms, confounded by other edaphic properties (e.g., pH, salinity), as well as the site-specific composition of the methanotrophic community. We hypothesize that this inconsistency may stem from the discrepancy in the cation adsorption capacity of the soil. We postulate that the effects of ammonium on the methanotrophic activity in soil are more accurately portrayed by relating methane uptake rates to the soluble ammonium (bioavailable), rather than the exchangeable (total) ammonium. To reduce adsorption (exchangeable) sites for ammonium in a paddy soil, two successive pre-incubation steps were introduced resulting in a 1000-fold soil dilution (soil enrichment), to be compared to a soil slurry (tenfold dilution) incubation. Ammonium was supplemented as $\mathrm{NH}_{4} \mathrm{Cl}$ at $0.5-4.75 \mathrm{gL}^{-1}$ after pre-incubation. While $\mathrm{NH}_{4} \mathrm{Cl}$ significantly stimulated the methanotrophic activity at all concentrations in the soil slurry incubation, methane uptake showed a dose-dependent effect in the soil enrichment. The trend in methane uptake could be explained by the soluble ammonium concentration, which was proportionate to the supplemented ammonium in the soil enrichment. In the soil slurry incubation, a fraction (36-63\%) of the supplemented ammonium was determined to be adsorbed to the soil. Accordingly, Methylosarcina was found to predominate the methanotrophic community after the incubation, suggesting the relevance of this methanotroph at elevated ammonium levels $\left(<3.25 \mathrm{gL}^{-1} \mathrm{NH}_{4} \mathrm{Cl}\right)$. Collectively, our results showed that the soluble, rather than the exchangeable ammonium concentration, is relevant when determining the effects of ammonium on methane oxidation, but this does not exclude other (a)biotic factors concurrently influencing methanotrophic activity.
\end{abstract}

Keywords Methanotroph $\cdot p m o A \cdot$ Ammonium-based fertilization $\cdot$ Wetland agriculture $\cdot$ Methylosarcina

\section{Introduction}

Hester van Dijk and Thomas Kaupper contributed equally to this work.

Marcus A. Horn

horn@ifmb.uni-hannover.de

Adrian Ho

adrian.ho@ifmb.uni-hannover.de

1 Institute for Microbiology, Leibniz Universität Hannover, Herrenhäuser Str. 2, 30419 Hannover, Germany

2 Department of Biology, Kunsan National University, Gunsan, Republic of Korea

3 Department of Microbial Ecology, Netherlands Institute of Ecology (NIOO-KNAW), Droevendaalsesteeg 10, 6708 PB Wageningen, the Netherlands

4 Division of Applied Life Science, Gyeongsang National University, Jinju, South Korea
The effects of ammonium on methane oxidation and the aerobic methanotrophs remain contentious, having been documented to stimulate and inhibit methanotrophic activity in the soil environment, as well as having no apparent effect whereby the ammonium-induced stimulation of methane oxidation is thought to be offset by the adverse effects (e.g., Alam and Jia 2012; Bodelier and Laanbroek 2004; Ji et al. 2020; Krause et al. 2012; Mohanty et al. 2006). Ammonia competitively inhibits methane oxidation, and accumulated products of ammonium oxidation (e.g., nitrite, hydroxylamine) can be toxic to the methanotrophs (Campbell et al. 2011; Nyerges et al. 2010; Nyerges and Stein 2009; Versantvoort et al. 2020). Earlier work showed that ammonium addition impaired methane uptake in soils (King and Schnell 1998; Schnell and King 1994). Paradoxically, 
ammonium-based fertilization may also stimulate methane oxidation particularly in agricultural, wetland soils where soil microorganisms compete with crops for limited $\mathrm{N}$ sources (e.g., Bodelier et al. 2000; Kaupper et al. 2020a).

The seemingly contradictory effects of ammonium on methane oxidation have been attributable to the dose and mineral forms of ammonium (e.g., ammonium chloride, ammonium sulfate) (Hu and Lu 2015; Krause et al. 2012; Mohanty et al. 2006; Walkiewicz et al. 2018; Xu and Inubushi 2004), as well as the methane concentration (King and Schnell 1998). Besides edaphic properties controlling methane oxidation (Ho et al. 2013a; Kaupper et al. 2020b), the methanotrophs, as well as the non-methanotrophic members of the community, are relevant biotic determinants potentially affecting the response of methane oxidation to external stressors, e.g., high ammonium input (Ho et al. 2020; Kaupper et al. 2020c; 2021; Mohanty et al. 2006). With prior or continuous exposure to ammonium, an ammonium-tolerant methanotrophic community may emerge over time (Ho et al. 2020; Qiu et al. 2008). Typically, the gammaproteobacterial methanotrophs (subgroup type Ia; Methylobacter, Methylomicrobium, Methylosarcina) are more responsive and show higher $\mathrm{N}$ assimilation, benefiting from short-term ammonium availability more than the alphaproteobacterial methanotrophs (subgroup type II; Methylocystis, Methylosinus) (Nold et al. 1999; Noll et al. 2008; Yang et al. 2020). Many type II methanotrophs (e.g., Methylocystis, Methylosinus, Methylocella), along with specific members of type I (Methylomonas), harbor the nifH gene (encoding for the nitrogenase), having the potential to fix molecular $\mathrm{N}$ and, hence, are competitively superior when $\mathrm{N}$ is limited (Graham et al. 1993; Ho and Bodelier 2015). Although canonical aerobic methanotrophs can be broadly grouped into Gammaproteobacteria, Alphaproteobacteria, and Verrucomicrobia based on their biochemistry, physiology, and associated life strategies, methanotrophs show species- and even strain-specific versatility in $\mathrm{N}$ metabolism (Ho et al. 2013a; Hoefman et al. 2014; Nyerges and Stein 2009). Therefore, a complex interaction of biotic and abiotic determinants underlies ammonium-induced effects on methane oxidation, which may be site-specific.

Previous studies documented the response of methane oxidation to the total or soluble ammonium after amendment (Table S1). Accordingly, ammonium depletion in soil amendment incubations is often attributed to biological ammonium consumption, which may be a cause for the seemingly contradictory findings given that ammonium (cation) is readily adsorbed to the negatively charged organic matter and soil particles (Ho et al. 2018; King and Schnell 1998). The adsorbed ammonium (non-soluble fraction) may not be fully accessible to soil microorganisms. Therefore, ammonium-induced effects could be misinterpreted in soil incubations, considering the total or exchangeable ammonium concentrations alone. Here, we hypothesized that the apparent inconsistency in ammonium-induced effects on methane oxidation may in part stem from differences in the adsorption capacity of the soil (as determined via the exchangeable and soluble ammonium fractions).

To address our hypothesis, we performed a systematic study using two series of incubations whereby the response in methanotrophic activity, community composition, and abundance in a paddy soil slurry (tenfold dilution) were compared to a soil enrichment (1000-fold dilution) incubation. We anticipate lower adsorption sites for ammonium in the soil enrichment than in the soil slurry incubations. As such, the effects of ammonium will be more accurately reflected in the soil enrichment incubation.

\section{Materials and methods}

The paddy soil was sampled in May 2015 from the CRA Agricultural Research Council, Rice Research Unit in Vercelli, Italy (coordinates, $45^{\circ} 20^{\prime} \mathrm{N}, 8^{\circ} 25^{\prime} \mathrm{E}$ ). Rice agriculture practice in the sampling site has been described before (Kaupper et al. 2021). After sampling, the soil was airdried at room temperature and sieved $(2 \mathrm{~mm})$ before being stored in a covered plastic container till experimental set up. The soil has a clay texture with a pH of 5.4 and a cation exchange capacity of $6.7 \mathrm{cmol}_{(+)} \mathrm{kg}^{-1}$ (Cucu et al. 2014). The soil contained a total $\mathrm{C}$ and $\mathrm{N}$ of $13.9 \mu \mathrm{g} \mathrm{C} \mathrm{mg} \mathrm{dw} \mathrm{soil}{ }^{-1}$ and $1.3 \mu \mathrm{g} \mathrm{N} \mathrm{mg} \mathrm{dw} \mathrm{soil}{ }^{-1}$, respectively (Ho et al. 2015). Selected nutrient contents include $\mathrm{NO}_{\mathrm{x}}$ ( sum of $\mathrm{NO}_{2}{ }^{-}$and $\mathrm{NO}_{3}{ }^{-}$), total $\mathrm{NH}_{4}{ }^{+}$, and $\mathrm{PO}_{4}{ }^{3-}$ of $34.4 \mu \mathrm{g} \mathrm{dw}$ soil ${ }^{-1}, 18.0 \mu \mathrm{g}$ $\mathrm{dw}$ soil $^{-1}$, and $0.6 \mu \mathrm{g} \mathrm{dw}$ soil $^{-1}$, respectively (Ho et al. 2015).

In both soil slurry and enrichment incubations, $\mathrm{NH}_{4} \mathrm{Cl}$ in ammonium mineral salts (AMS) was supplemented to a final concentration of 0.50 (referred to as treatment 1 , T1), 1.25 (T2), 2.00 (T3), 2.50 (T4), 3.25 (T5), and $4.75 \mathrm{~g}$ $\mathrm{L}^{-1}$ (T6), corresponding to $9.35,23.39,37.42,46.77$, 60.80 , and $88.87 \mathrm{mM} \mathrm{NH}_{4}{ }^{+}$, respectively (Fig. S1). In the reference incubation (T0), autoclaved $\mathrm{dH}_{2} \mathrm{O}$, instead of $\mathrm{NH}_{4} \mathrm{Cl}$-supplemented AMS, was added to the soil (Fig. S1). These concentrations were selected based on the effects of $\mathrm{NH}_{4} \mathrm{Cl}$ on the methane uptake rates in the same soil (i.e., dose-dependent inhibition of methane uptake was proportional to $\mathrm{NH}_{4} \mathrm{Cl}$ concentrations) (Ho et al. 2020). All incubations ( $\mathrm{n}=3$, each treatment) were performed in $120 \mathrm{ml}$ bottles under $2-3 \%_{\mathrm{v} / \mathrm{v}}$ methane in air at $27^{\circ} \mathrm{C}$ while shaking $(120 \mathrm{rpm})$ in the dark.

After the incubation, the samples were collected and stored in a $-20{ }^{\circ} \mathrm{C}$ freezer till DNA extraction for molecular analyses and ammonium and nitrate determination. The methanotrophic abundance and community composition were, respectively, determined by qPCR and Illumina MiSeq sequencing targeting the $p m o A$ gene (encoding for 
the particulate methane monooxygenase, pMMO). The pmoA gene sequences were deposited at the National Center for Biotechnology Information (NCBI) under the accession number PRJNA691142. The ammonium concentration was determined using standard colorimetric methods as described before (Ho et al. 2020). Exchangeable ammonium, regarded as the total amount of ammonium present, was determined in $2 \mathrm{M} \mathrm{KCl}(1: 2)$ after filtration $(0.22 \mu \mathrm{m})$, whereas soluble ammonium was determined in the liquid phase of the soil slurry and enrichment, after centrifugation and filtration $(0.22 \mu \mathrm{m})$. The soluble ammonium was regarded as the ammonium fraction largely accessible to the microorganisms (bioavailable). The detailed experimental setup and molecular analyses are given in the Supplementary Information.

\section{Results and discussion}

\section{Dose-dependent effect of soluble ammonium on methane uptake rates}

Methane was rapidly consumed within 2-3 days after $\mathrm{NH}_{4} \mathrm{Cl}$ addition in all the soil slurry incubations (T1-T6) when compared to the reference incubation (T0), where headspace methane decreased by $<50 \%_{\mathrm{v} / \mathrm{v}}$ even after 7 days, indicating that supplemented $\mathrm{NH}_{4} \mathrm{Cl}$ in $\mathrm{AMS}$ stimulated methane uptake rates (Fig. 1a, c). On the other hand, $\mathrm{NH}_{4} \mathrm{Cl}$-induced stimulation of methane uptake was dose-dependent in the soil enrichment (Fig. 1b, d), where the stimulatory effect was significant at $<2.50 \mathrm{gL}^{-1} \mathrm{NH}_{4} \mathrm{Cl}$ (T4). Although methane uptake was still detected in the 3.25 and $4.75 \mathrm{gL}^{-1}$ $\mathrm{NH}_{4} \mathrm{Cl}$-supplemented incubations (T5 and T6), the uptake rates were comparable to the reference (T0) incubation. Therefore, optimum methane uptake occurred at $<2.50$ $\mathrm{gL}^{-1} \mathrm{NH}_{4} \mathrm{Cl}$ in the soil enrichment incubation, whereas the $\mathrm{NH}_{4} \mathrm{Cl}$-induced stimulatory effect in the soil slurry incubation seemingly occurred at all $\mathrm{NH}_{4} \mathrm{Cl}$-supplemented concentrations.

Methane uptake could be related particularly to the soluble ammonium concentration in both soil slurry and enrichment incubations. Soluble ammonium was appreciably lower than the total ammonium concentration in all soil slurry incubations after 5 days, indicating biological ammonium uptake and/or adsorption of a large fraction of the ammonium to the soil (Fig. 2). Considering the relatively little change in the initial total ammonium concentration after the incubation (i.e., total ammonium uptake; Fig. 2a), the appreciably lower soluble ammonium concentration detected is more likely caused by a higher adsorption to the soil than microbially mediated ammonium consumption. To additionally assess the contribution of biological ammonium consumption, future studies could employ isotopically labeled ammonium to track ammonium-derived nitrate (i.e., microbially mediated nitrification) after saturating the soil (and hence, adsorption sites) with unlabeled ammonium. It appears that the supplemented ammonium levels did not reflect on the amounts accessible to the microorganisms, where approximately $36-63 \%$ of supplemented ammonium (i.e., difference in the total and soluble ammonium fraction relative to the initial supplemented concentration) was adsorbed to the soil (Fig. 2).

In contrast, soluble ammonium concentrations commensurate with the $\mathrm{NH}_{4} \mathrm{Cl}$-supplemented amount in the soil enrichment incubations (Fig. 2b). Here, at $<3.25 \mathrm{gL}^{-1}$ $\mathrm{NH}_{4} \mathrm{Cl}$ (T5), the mean soluble ammonium concentrations after the incubation were lower or comparable to the initial values and were proportionate to the supplemented concentrations (Fig. 2b). In the soil enrichment supplemented with $4.75 \mathrm{gL}^{-1} \mathrm{NH}_{4} \mathrm{Cl}$ (T6), however, ammonium concentration was higher after the incubation, possibly released by lysed cells of organisms adversely affected by the inhibitory ammonium levels. The inhibitory effect was corroborated by the significantly lower methane uptake and methanotrophic abundance when compared to incubations supplemented with lower $\mathrm{NH}_{4} \mathrm{Cl}$ concentrations (Figs. 1 and 3). Therefore, methane uptake taken together with the methanotrophic abundance and ammonium concentrations after the soil enrichment incubation indicates that supplemented $\mathrm{NH}_{4} \mathrm{Cl}$ was largely accessible to the methanotrophs and could explain the dose-dependent effect on methanotrophic activity (i.e., stimulation at $<2.5 \mathrm{gL}^{-1} \mathrm{NH}_{4} \mathrm{Cl}$ and inhibition at $4.75 \mathrm{gL}^{-1} \mathrm{NH}_{4} \mathrm{Cl}$ ). Since soluble ammonium concentration was appreciably lower $\left(<1.6 \mathrm{gL}^{-1} \mathrm{NH}_{4} \mathrm{Cl}\right)$ in all soil slurry incubations, methane uptake was seemingly stimulated, regardless of the supplemented $\mathrm{NH}_{4} \mathrm{Cl}$ concentrations (Figs. 1 and 2). Hence, ammonium-induced effects can be influenced by the ion exchange capacity (adsorption/desorption) of the mineral form of ammonium in different soils (King and Schnell 1998). In agreement with our hypothesis, the soluble ammonium, rather than the total ammonium fraction, is relevant to determine ammonium-induced response in methane uptake.

The effects of $\mathrm{NH}_{4} \mathrm{Cl}$ addition on the methanotrophic activity may be confounded by other parameters (e.g., AMS-derived copper, salt stress, nitrate, and $\mathrm{pH}$ ) (DiSpirito et al. 2016; Ho et al. 2013b; 2018; Figs. S2 and S3) during the incubation. Although we cannot completely exclude the effects of these confounding factors, the response in methane uptake appears to be largely induced by the supplemented $\mathrm{NH}_{4} \mathrm{Cl}$ in AMS, extended discussion given in the Supplementary Information. 

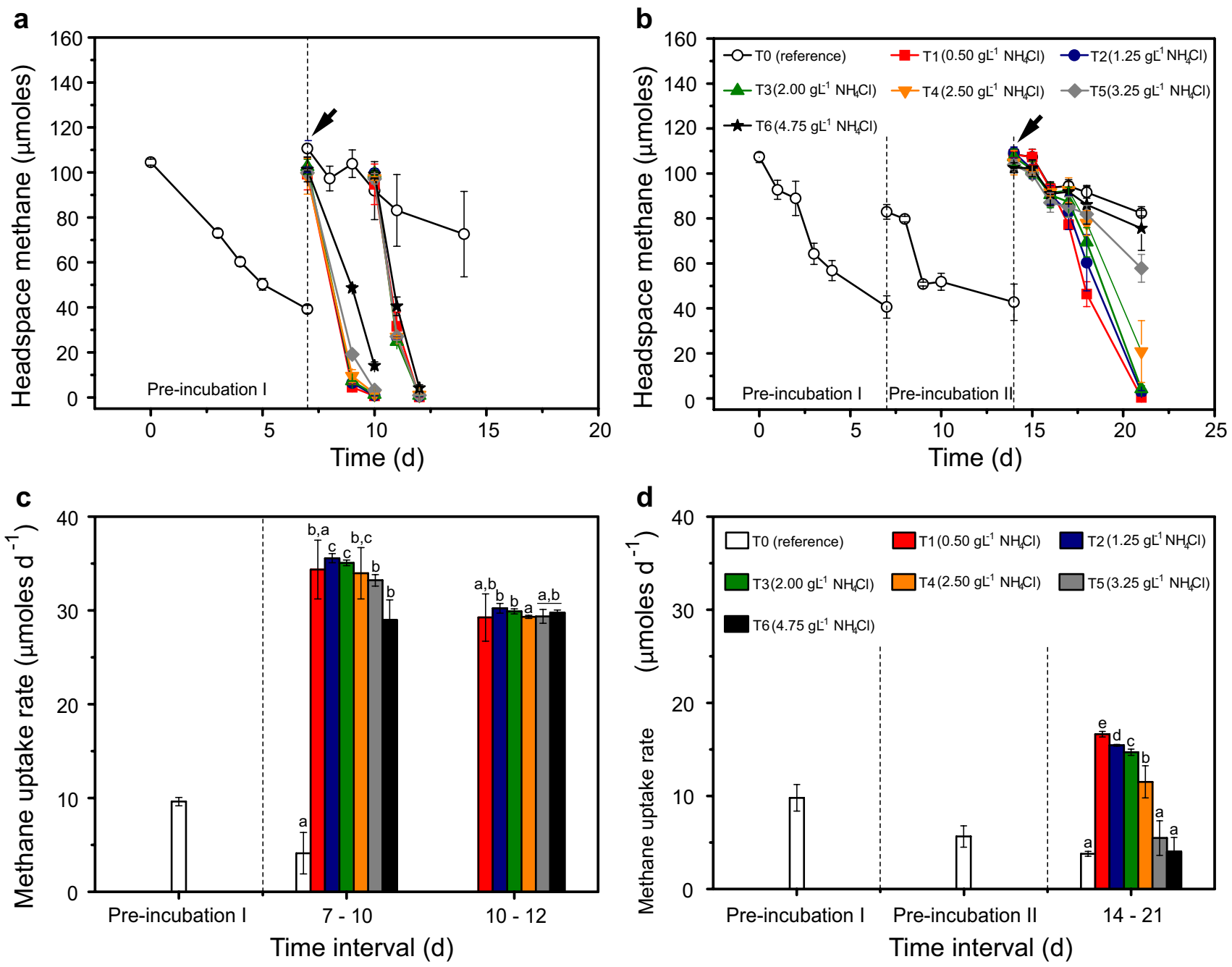

Fig. 1 Methane uptake in the soil slurry (a, c) and soil enrichment (b, d) incubations (mean \pm s.d., $n=3$ ). The methane uptake rates (c, d) were determined by linear regression from the depletion of headspace methane during incubation (a, b). The soil slurry and enrichment incubations were performed using the same paddy soil. Arrows indicate when $\mathrm{NH}_{4} \mathrm{Cl}$-AMS was supplemented after pre-incubation.

\section{Response of the methanotrophic abundance and community composition to $\mathrm{NH}_{4} \mathrm{Cl}-\mathrm{AMS}$ amendments}

The $p m o A$ gene abundance, which determines the abundance of the methanotrophs, was significantly higher after incubation in T4 to T6 in the soil slurry incubations relative to the reference and starting (after pre-incubation) values (Fig. 3). Although the mean $p m o A$ gene abundance gradually increased in the soil slurry from $\mathrm{T} 1$ to $\mathrm{T} 3$, the values were not significantly different. On the other hand, the significant increase $(\mathrm{p}<0.05)$ in the $p m o A$ gene abundance ( $\mathrm{T} 1$ to $\mathrm{T} 4)$ in the soil enrichment is not consistent with the decreasing methane uptake rates (Figs. 1 and 3). Although statistically
The pre-incubation was performed to allow the methanotrophs to grow and, hence, having more comparable starting abundances in the soil slurry and enrichment while diluting the soil particles to reduce ammonium adsorption sites. The level of significance $(\mathrm{p}<0.05)$ is indicated by the lower case letters. Note the different scales of the y-axes

significant, the mean $p m o A$ gene abundances in $\mathrm{T} 1$ to $\mathrm{T} 4$ were within a relatively narrow range $\left(3.5 \times 10^{6}\right.$ to $2.0 \times 10^{7}$ pmoA copy no. $\mathrm{ml}^{-1}$ ). Admittedly, the DNA-based qPCR analysis may not be as sufficiently sensitive as other biological indicators (e.g., transcript-based analyses) to capture relatively subtle differences, as detected in the activity measurements, likely being obscured by persistent relic DNA in the soil matrix (Carini et al. 2017; Schloter et al. 2018). Nevertheless, the qPCR was effective at capturing more pronounced differences (Ho et al. 2015; Reumer et al. 2018); the severe inhibition in methane uptake rate in T6 is clearly reflected in the appreciably lower mean $p m o A$ gene abundance (1-2 orders of magnitude) when compared to the other treatments in the soil enrichment (Figs. 1d and 3). 

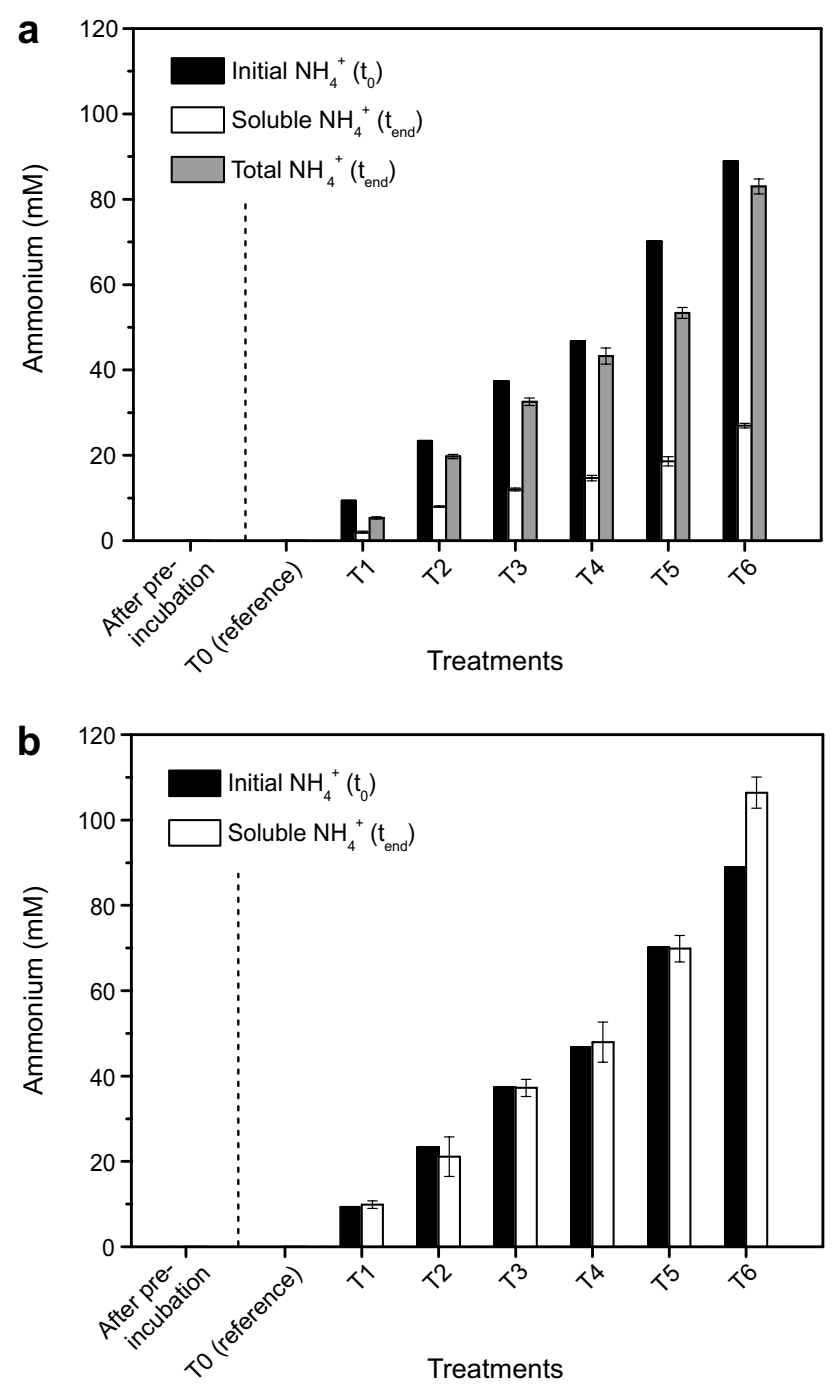

Fig. 2 Changes in exchangeable ammonium, representing the total ammonium fraction and/or soluble ammonium concentration in the soil slurry (a) and soil enrichment (b) incubations. The ammonium concentration was determined in duplicate for each sample $(n=3)$, yielding a total of 6 replicates per treatment. The initial ammonium concentration $\left(\mathrm{t}_{0}\right)$ was theoretically determined from the supplemented $\mathrm{NH}_{4} \mathrm{Cl}$-AMS. Ammonium concentration was measured after the incubation $\left(\mathrm{t}_{\mathrm{end}}\right)$ for all treatments. Ammonium concentration in the starting material prior to $\mathrm{NH}_{4} \mathrm{Cl}$-AMS addition and in the reference (T0) after incubation were below the detection limit of the colorimetric assay $(<0.02 \mathrm{mM})$. In a, the total ammonium concentration was significantly $(\mathrm{p}<0.05)$ higher than in the soluble fraction after incubation in T1 to T6. In $\mathbf{b}$, only the soluble ammonium concentration was determined because the soil was no longer visibly present after a 1000 -fold dilution

To account for the discrepancy in the initial pmoA gene abundances in the soil slurry and enrichment incubations (soil slurry, $5.0 \times 10^{6}$ pmoA copy no. g soil ${ }^{-1}$; soil enrichment, $1.6 \times 10^{5}$ pmoA copy no. $\mathrm{ml}^{-1}$; Fig. 3 ), we determined the magnitude increase in the $p m o A$ gene abundance for the $\mathrm{NH}_{4} \mathrm{Cl}$-supplemented incubations that were significantly higher relative to the initial pmoA gene abundance (i.e., soil slurry, T4-T6; soil enrichment, T1-T5; Fig. 3). During the soil slurry incubation, the mean pmoA gene abundance increased by 6.7-fold, 10.7-fold, and 13.9-fold, respectively, in T4, T5, and T6, whereas a 22.5-fold, 41.0-fold, 47.0-fold, 134.0-fold, and 48.3-fold increase were detected in the T1, T2, T3, T4, and T5 soil enrichment incubations, respectively. The difference in the $p m o A$ gene abundance (initial and after incubation) indicates methanotrophic growth.

The response of the methanotrophic community composition to the added $\mathrm{NH}_{4} \mathrm{Cl}$ was visualized as a principal component analysis (PCA), based on the pmoA gene sequences (Figs. 3 and S4). Notably, introducing two successive pre-incubation steps (Fig. S1) in the soil enrichment altered the composition of the methanotrophs; compared to the soil slurry incubation, methanotrophs belonging to the rice paddy cluster (RPC) decreased in relative abundance in the soil enrichment (Fig. S4). Nevertheless, the predominant methanotrophs in both the soil slurry and enrichment consistently comprised of Methylosarcina (type Ia) and other members of gammaproteobacterial methanotrophs (RPC and other uncultured type Ib methanotrophs), as well as alphaproteobacterial methanotrophs belonging to Methylocystis (type II) (Figs. 3 and S4). These taxa collectively represent $>90 \%$ of the total methanotrophic population in all incubations. A compositional shift in the methanotrophic community was detected in the soil slurry incubations, whereby Methylosarcina became dominant with increasing $\mathrm{NH}_{4} \mathrm{Cl}$ concentrations, diverging from the community in the reference incubation (Fig. 3). Methylosarcina also predominate the population at $<3.25 \mathrm{gL}^{-1} \mathrm{NH}_{4} \mathrm{Cl}$ (T5) in the soil enrichment, but community composition in $\mathrm{T} 6$ and reference incubations were more similar (Fig. 3).

Methylosarcina was favored in both the soil slurry and enrichment with increasing supplemented $\mathrm{NH}_{4} \mathrm{Cl}$ after incubation, despite of the discrepancy in the composition of the methanotrophic community prior to $\mathrm{NH}_{4} \mathrm{Cl}$ addition (Figs. 3 and S4). This indicates that $\mathrm{NH}_{4} \mathrm{Cl}$ strongly influenced the community composition during the incubation. However, the relative abundance of Methylosarcina decreased in the soil enrichment supplemented with $4.75 \mathrm{gL}^{-1} \mathrm{NH}_{4} \mathrm{Cl}$ (T6), corresponding to significantly lower methanotrophic activity, suggesting that this methanotroph contributed to methane oxidation under moderate $\mathrm{NH}_{4} \mathrm{Cl}$ levels (up to $3.25 \mathrm{gL}^{-1}$, T5). This is not surprising given that gammaproteobacterial methanotrophs of subgroup type Ia are thought to be rapid responders to substrate availability (Ho et al. 2013a; 2017) and would benefit from the sudden availability of extraneous nitrogen sources. Indeed, besides Methylosarcina, other type Ia methanotrophs (e.g., Methylobacter and Methylomicrobium) have been consistently enriched after ammonium amendments in short-term incubations and showed higher $\mathrm{N}$ assimilation ( $\mathrm{Hu}$ and $\mathrm{Lu} 2015$; Nold et al. 1999; Noll 


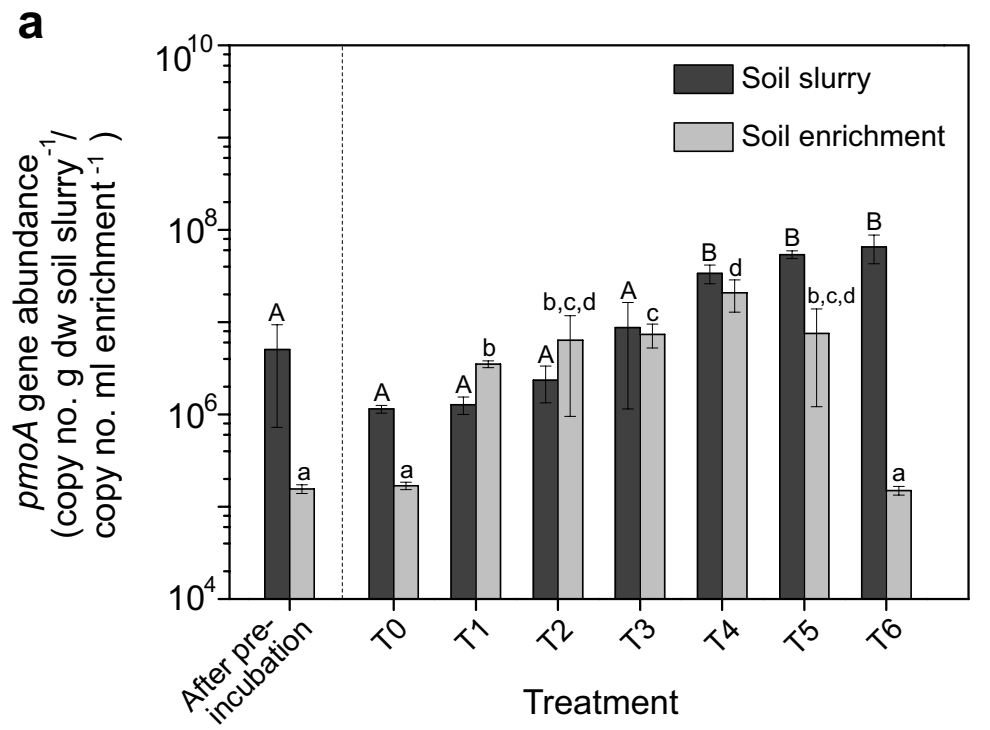

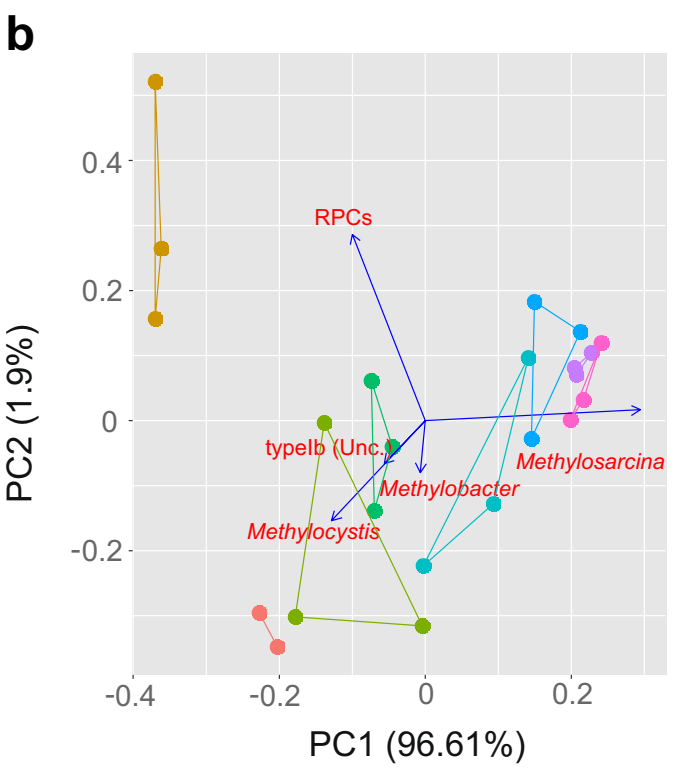

Fig. 3 Changes in the methanotrophic abundance (a) and community composition in the soil slurry (b) and enrichment (c) incubations, based on the pmoA gene targeted using the primer combination A189f/mb661r. In a, the qPCR assay was performed in duplicate for each sample $(n=3)$, yielding a total of 6 replicates per treatment; upper and lower case letters indicate the level of significance $(\mathrm{p}<0.05)$ between treatments in the soil slurry and enrichment, respectively. The lower detection limit of the qPCR assay was at approximately $2.5-5.0 \times 10^{3}$ copy no. pmoA gene $\mathrm{g} \mathrm{dw}$ soil slurry ${ }^{-1}$

et al. 2008; Yang et al. 2020). In line with previous studies (e.g., Alam and Jia 2012; Bodelier et al. 2000; Noll et al. 2008; Qiu et al. 2008), the apparent stimulation of type Ia methanotrophs can be attributable to a relief of $\mathrm{N}$ limitation, as indicated by the significant $\mathrm{NH}_{4} \mathrm{Cl}$-induced stimulation (exception, $4.75 \mathrm{gL}^{-1} \mathrm{NH}_{4} \mathrm{Cl}$ in the soil enrichment) of methanotrophic activity.

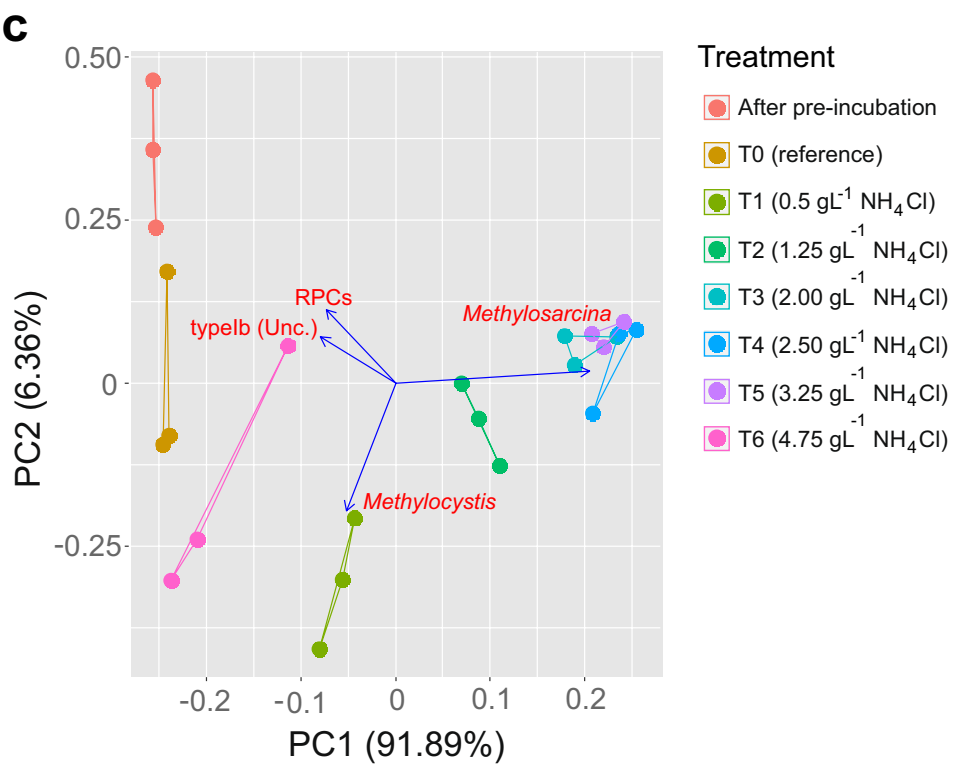

or $\mathrm{ml}$ enrichment ${ }^{-1}$. In $\mathbf{b}$ and $\mathbf{c}$, the response of the methanotrophic community composition to supplemented $\mathrm{NH}_{4} \mathrm{Cl}$ in AMS is visualized by a principal component analysis (PCA). All replicates were included for the ordination. Note that in $\mathbf{b}$, pmoA gene sequencing was not successful for one replicate after pre-incubation. In the PCA, the vectors represent the predominant methanotrophs (see also Fig. S4). Abbreviations: RPC, rice paddy cluster; Unc, uncultured methanotrophs

Contrastingly, an alphaproteobacterial methanotroph, Methylocystis, was enriched in incubations of the same soil where $\mathrm{NH}_{4} \mathrm{Cl}$ concentration was increased step-wise from 0.5 to $4.75 \mathrm{gL}^{-1}$ at $0.25 \mathrm{gL}^{-1}$ increments (Ho et al. 2020). Because of the prolonged incubation over approximately 3 months with a constantly increasing selection pressure (elevated $\mathrm{NH}_{4} \mathrm{Cl}$ concentrations), the predominant 
ammonium-tolerant methanotroph that emerged is presumably able to detoxify products of ammonium oxidation (i.e., hydroxylamine, nitrite, nitrate (Ho et al. 2020; López et al. 2019; Versantvoort et al. 2020). Although further oxidation of hydroxylamine and nitrite is not confined to specific methanotroph subgroups (Hoefman et al. 2014; Nyerges and Stein 2009; Poret-Peterson et al. 2008), some Methylocystis appear to be more effective at detoxifying products of ammonium oxidation and hence were relatively more tolerant to ammonium inhibition (Nyerges and Stein 2009). Recently, a hydroxylamine oxidoreductase (responsible for the oxidation of hydroxylamine to nitric oxide) was purified from Methylacidiphilum fumariolicum SolV, a thermophilic verrucomicrobial methanotroph, but is also likely to occur in other aerobic methanotrophs (Versantvoort et al. 2020). Therefore, different mechanisms may underlie the selection of the gammaproteobacterial (including Methylosarcina) and alphaproteobacterial (including Methylocystis) methanotrophs at high ammonium levels. While a relief of $\mathrm{N}$ limitation may favor members of gammaproteobacterial methanotrophs in the short-term as in this study, metabolic capacity to detoxify inhibitory compounds of ammonium oxidation may become relevant over time, determining the fitness and dominance of specific methanotrophs.

\section{Conclusion}

We provide a simple, yet plausible reason for the inconsistent documented response of the methanotrophic activity and community composition to ammonium amendment in the soil environment. Our findings do not preclude other (a)biotic determinants occurring concurrently, affecting the response of the methanotrophic activity to ammonium. Not all ammonium will be accessible to the microorganisms. A considerable fraction (36-63\%) of the supplemented ammonium can be adsorbed by the soil. Therefore, considering the total ammonium alone may not reflect on the actual ammonium-induced effects on the methanotrophic activity and community composition at the supplemented concentrations. Based on these results, we advocate determining the (i) ammonium fraction that is available to the microorganisms and/or (ii) total ammonium over time, enabling the determination of the baseline ammonium level (i.e., the fraction likely adsorbed to the soil), when documenting ammonium-induced effects on methane uptake. Given that the methanotrophs are differentially affected by the supplemented ammonium, the diversity of the methanotrophs is thus relevant to sustain methanotrophic activity at high ammonium concentrations.

Supplementary Information The online version contains supplementary material available at https://doi.org/10.1007/s00374-021-01579-9.
Author contribution All authors have seen and approved the final version submitted.

Funding Open Access funding enabled and organized by Projekt DEAL. TK and AH are financially supported by the Deutsche Forschungsgemeinschaft (grant no. HO6234/1-1). AH and MAH are also financially supported by the Leibniz Universität Hannover, Germany.

\section{Declaration}

Conflict of interest The authors declare no competing interests.

Open Access This article is licensed under a Creative Commons Attribution 4.0 International License, which permits use, sharing, adaptation, distribution and reproduction in any medium or format, as long as you give appropriate credit to the original author(s) and the source, provide a link to the Creative Commons licence, and indicate if changes were made. The images or other third party material in this article are included in the article's Creative Commons licence, unless indicated otherwise in a credit line to the material. If material is not included in the article's Creative Commons licence and your intended use is not permitted by statutory regulation or exceeds the permitted use, you will need to obtain permission directly from the copyright holder. To view a copy of this licence, visit http://creativecommons.org/licenses/by/4.0/.

\section{References}

Alam MS, Jia Z (2012) Inhibition of methane oxidation by nitrogenous fertilizers in a paddy soil. Front Microbiol 3:246. https://doi.org/ 10.3389/fmicb.2012.00246

Bodelier PLE, Laanbroek HJ (2004) Nitrogen as a regulatory factor of methane oxidation in soils and sediments. FEMS Microbiol Ecol 47:265-277. https://doi.org/10.1016/S0168-6496(03)00304-0

Bodelier PLE, Roslev P, Henckel T, Frenzel P (2000) Stimulation by ammonium-based fertilizers of methane oxidation in soil around rice roots. Nature 403:421-424. https://doi.org/10.1038/35000193

Campbell MA, Nyerges G, Kozlowski JA, Poret-Peterson AT, Stein LY, Klotz MG (2011) Model of the molecular basis for hydroxylamine oxidation and nitrous oxide production in methanotrophic bacteria. FEMS Microbiol Lett 322:82-89. https://doi.org/10.1111/j. 1574-6968.2011.02340.x

Carini P, Marsden PJ, Leff JW, Morgan EE, Strickland MS, Fierer N (2017) Relic DNA is abundant in soil and obscures estimates of soil microbial diversity. Nat Microbiol 2:16242. https://doi.org/ 10.1038/nmicrobiol.2016.242

Cucu MA, Said-Pullicino D, Maurino V, Bonifacio E, Romani M, Celi L (2014) Influence of redox conditions and rice straw incorporation on nitrogen availability in fertilized paddy soils. Biol Fertil Soils 50:755-764. https://doi.org/10.1007/s00374-013-0893-4

DiSpirito AA, Semrau JD, Murrell JC, Gallagher WH, Dennison C, Vuilleumier S (2016) Methanobactin and the Link between copper and bacterial methane oxidation. Microbiol Mol Biol Rev 80:387-409. https://doi.org/10.1128/MMBR.00058-15

Graham DW, Chaudhary JA, Hanson RS, Arnold RG (1993) Factors affecting competition between type I and type II methanotrophs in two-organism, continuous-flow reactors. Microb Ecol 25:1-17. https://doi.org/10.1007/BF00182126

Ho A, Bodelier PLE (2015) Diazotrophic methanotrophs in peatlands: the missing link? Plant Soil 389:419-423. https://doi.org/10.1007/ s11104-015-2393-9 
Ho A, Kerckhof F-M, Luke C, Reim A, Krause S, Boon N, Bodelier PLE (2013a) Conceptualizing functional traits and ecological characteristics of methane-oxidizing bacteria as life strategies. Environ Microbiol Rep 5:335-345. https://doi.org/10.1111/j. 1758-2229.2012.00370.x

Ho A, Lüke C, Reim A, Frenzel P (2013b) Selective stimulation in a natural community of methane oxidizing bacteria: effects of copper on pmoA transcription and activity. Soil Biol Biochem 65:211-216. https://doi.org/10.1016/j.soilbio.2013.05.027

Ho A, El-Hawwary A, Kim SY, Meima-Franke M, Bodelier P (2015) Manure-associated stimulation of soil-borne methanogenic activity in agricultural soils. Biol Fertil Soils 51:511-516. https://doi. org/10.1007/s00374-015-0995-2

Ho A, Di Lonardo DP, Bodelier PLE (2017) Revisiting life strategy concepts in environmental microbial ecology. FEMS Microbiol Ecol 93:fix006. https://doi.org/10.1093/femsec/fix006

Ho A, Mo Y, Lee HJ, Sauheitl L, Jia Z, Horn MA (2018) Effect of salt stress on aerobic methane oxidation and associated methanotrophs; a microcosm study of a natural community from a nonsaline environment. Soil Biol Biochem 125:210-214. https://doi. org/10.1016/j.soilbio.2018.07.013

Ho A, Mendes LW, Lee HJ, Kaupper T, Mo Y, Poehlein A, Bodelier PLE, Jia Z, Horn MA (2020) Response of a methane-driven interaction network to stressor intensification. submitted. FEMS Microbiol Ecol 96. https://doi.org/10.1093/femsec/fiaa180

Hoefman S, van der Ha D, Boon N, Vandamme P, Vos P de, Heylen K (2014) Niche differentiation in nitrogen metabolism among methanotrophs within an operational taxonomic unit. BMC Microbiol 14:83. https://doi.org/10.1186/1471-2180-14-83

$\mathrm{Hu} \mathrm{A}, \mathrm{Lu}$ Y (2015) The differential effects of ammonium and nitrate on methanotrophs in rice field soil. Soil Biol Biochem 85:31-38. https://doi.org/10.1016/j.soilbio.2015.02.033

Ji Y, Conrad R, Xu H (2020) Responses of archaeal, bacterial, and functional microbial communities to growth season and nitrogen fertilization in rice fields. Biol Fertil Soils 56:81-95. https://doi. org/10.1007/s00374-019-01404-4

Kaupper T, Hetz S, Kolb S, Yoon S, Horn MA, Ho A (2020a) Deforestation for oil palm: impact on microbially mediated methane and nitrous oxide emissions, and soil bacterial communities. Biol Fertil Soils 56:287-298. https://doi.org/10.1007/s00374-019-01421-3

Kaupper T, Luehrs J, Lee HJ, Mo Y, Jia Z, Horn MA, Ho A (2020b) Disentangling abiotic and biotic controls of aerobic methane oxidation during re-colonization. Soil Biol Biochem 142:107729. https://doi.org/10.1016/j.soilbio.2020.107729

Kaupper T, Mendes LW, Harnisz M, Krause SMB, Horn MA, Ho A (2020c) Recovery in methanotrophic activity does not reflect on the methane-driven interaction network after peat mining. Appl Environ Microbiol 87:e02355-e2420. https://doi.org/10.1128/ AEM.02355-20

Kaupper T, Mendes LW, Lee HJ, Mo Y, Poehlein A, Jia Z, Horn MA, Ho A (2021) When the going gets tough: emergence of a complex methane-driven interaction network during recovery from desiccation-rewetting. Soil Biol Biochem 153:108109. https://doi. org/10.1016/j.soilbio.2020.108109

King GM, Schnell S (1998) Effects of ammonium and non-ammonium salt additions on methane oxidation by Methylosinus trichosporium OB3b and Maine forest soils. Appl Environ Microbiol 64:253-257. https://doi.org/10.1128/AEM.64.1.253-257.1998

Krause S, Lüke C, Frenzel P (2012) Methane source strength and energy flow shape methanotrophic communities in oxygen-methane counter-gradients. Environ Microbiol Rep 4:203-208. https:// doi.org/10.1111/j.1758-2229.2011.00322.x

López JC, Porca E, Collins G, Clifford E, Quijano G, Muñoz R (2019) Ammonium influences kinetics and structure of methanotrophic consortia. Waste Manag 89:345-353. https://doi.org/10.1016/j. wasman.2019.04.028

Mohanty SR, Bodelier PLE, Floris V, Conrad R (2006) Differential effects of nitrogenous fertilizers on methane-consuming microbes in rice field and forest soils. Appl Environ Microbiol 72:13461354. https://doi.org/10.1128/AEM.72.2.1346-1354.2006

Nold SC, Boschker HT, Pel R, Laanbroek HJ (1999) Ammonium addition inhibits $13 \mathrm{C}$-methane incorporation into methanotroph membrane lipids in a freshwater sediment. FEMS Microbiol Ecol 29:81-89. https://doi.org/10.1111/j.1574-6941.1999.tb00600.x

Noll M, Frenzel P, Conrad R (2008) Selective stimulation of type I methanotrophs in a rice paddy soil by urea fertilization revealed by RNA-based stable isotope probing. FEMS Microbiol Ecol 65:125-132. https://doi.org/10.1111/j.1574-6941.2008.00497.x

Nyerges G, Stein LY (2009) Ammonia cometabolism and product inhibition vary considerably among species of methanotrophic bacteria. FEMS Microbiol Lett 297:131-136. https://doi.org/10. 1111/j.1574-6968.2009.01674.x

Nyerges G, Han S-K, Stein LY (2010) Effects of ammonium and nitrite on growth and competitive fitness of cultivated methanotrophic bacteria. Appl Environ Microbiol 76:5648-5651. https://doi.org/ 10.1128/AEM.00747-10

Poret-Peterson AT, Graham JE, Gulledge J, Klotz MG (2008) Transcription of nitrification genes by the methane-oxidizing bacterium, Methylococcus capsulatus strain Bath. ISME J 2:12131220. https://doi.org/10.1038/ismej.2008.71

Qiu Q, Noll M, Abraham W-R, Lu Y, Conrad R (2008) Applying stable isotope probing of phospholipid fatty acids and rRNA in a Chinese rice field to study activity and composition of the methanotrophic bacterial communities in situ. ISME J 2:602-614. https://doi.org/ 10.1038/ismej.2008.34

Reumer M, Harnisz M, Lee HJ, Reim A, Grunert O, Putkinen A, Fritze H, Bodelier PLE, Ho A (2018) Impact of peat mining and restoration on methane turnover potential and methane-cycling microorganisms in a northern bog. Appl Environ Microbiol 84:e02218-e2317. https://doi.org/10.1128/AEM.02218-17

Schloter M, Nannipieri P, Sørensen SJ, van Elsas JD (2018) Microbial indicators for soil quality. Biol Fertil Soils 54:1-10. https://doi. org/10.1007/s00374-017-1248-3

Schnell S, King GM (1994) Mechanistic analysis of ammonium inhibition of atmospheric methane consumption in forest soils. Appl Environ Microbiol 60:3514-3521

Versantvoort W, Pol A, Jetten MSM, van Niftrik L, Reimann J, Kartal B, Op den Camp HJM (2020) Multiheme hydroxylamine oxidoreductases produce NO during ammonia oxidation in methanotrophs. Proc Natl Acad Sci U S A 117:24459-24463. https:// doi.org/10.1073/pnas.2011299117

Walkiewicz A, Brzezińska M, Bieganowski A (2018) Methanotrophs are favored under hypoxia in ammonium-fertilized soils. Biol Fertil Soils 54:861-870. https://doi.org/10.1007/s00374-018-1302-9

Xu X, Inubushi K (2004) Effects of N sources and methane concentrations on methane uptake potential of a typical coniferous forest and its adjacent orchard soil. Biol Fertil Soils 40:215-221. https:// doi.org/10.1007/s00374-004-0768-9

Yang Y, Tong T, Chen J, Liu Y, Xie S (2020) Ammonium impacts methane oxidation and methanotrophic community in freshwater sediment. Front Bioeng Biotechnol 8:250. https://doi.org/10.3389/ fbioe. 2020.00250

Publisher's Note Springer Nature remains neutral with regard to jurisdictional claims in published maps and institutional affiliations. 